\title{
ANÁLISE DA COMPATIBILIDADE DA ARBORIZAÇÃO VIÁRIA COM O AMBIENTE CONSTRUÍDO NA CIDADE DE LUIZIANA, PARANÁ, BRASIL
}

\author{
Larissa Fernanda Vieira Martins ${ }^{1}$, Helisson Henrique Borsato de Andrade $^{2}$, Rogério \\ Fernandes Hanisch ${ }^{3}$, Bruno Luiz Domingos De Angelis ${ }^{4}$, Marcelo Galeazzi Caxambu ${ }^{5}$
}

(recebido em 21.05.2010 e aceito para publicação em 15.09.2011)

\section{RESUMO}

A arborização urbana é de suma importância ao ambiente construído por propiciar melhorias nos aspectosfísicos, ecológicos e sociais deste meio. Para que ocorram tais melhorias, é necessário equilíbrio entre os elementos artificiais e naturais do ambiente. $O$ objetivo desta pesquisa foi à análise da compatibilidade da arborização viáriacom as infraestruturas urbanas de Luiziana, Paraná. A pesquisa utilizou-se de inventário em oito vias da cidade, onde se analisou o comportamento dos espécimes vegetais em campo no tocante a relação planta/infraestrutura. Foram identificados 1540 indivíduos vegetais, distribuídos em 47 espécies, 38 gêneros e 24 famílias botânicas, onde, Ligustrum lucidum, Caesalpinia pluviosa, Schinus molle e Murraya paniculata são as espécies predominantes, representando $73,18 \%$ da arborização trabalhada. A cidade apresenta problemas relacionados ao manejo das árvores, fator evidenciado uma vez que $88 \%$ das árvores possuem altura da $1^{\circ}$ bifurcação inferior a 1,80 metros. Constatou-se problemas relacionados à quebra do calçamento ocasionado pelo sistema radicular da planta. Para tanto se faznecessário o (re) planejamento da arborização com o intuito de promover melhorias nos incômodos físicos e visuais ocasionados pela incompatibilidade das árvores para com os demais elementos da paisagem urbana.

\footnotetext{
${ }^{1}$ Tecnóloga Ambiental, Doutoranda em Geografia Física - Faculdade de Filosofia Letras e Ciências Humanas FFLCH, Universidade de São Paulo - São Paulo-SP.larissafernanda@usp.br

${ }^{2}$ Tecnólogo Ambiental, Mestrando em Engenharia Civil, Universidade Tecnológica Federal do Paraná - UTFPR, Curitiba-PR. helissonborsato@gmail.com

${ }^{3}$ Bacharel em Ciências Biológicas. rfernandeshanisch@grupointegrado.br

${ }^{4}$ Professor Doutor em Geografia. Departamento de Agronomia, Universidade Estadual de Maringá UEM, Maringá-PR. brucagen@uol.com.br

${ }^{5}$ Professor Doutor em Ciências. Departamento de Tecnologia e Engenharia Ambiental, Universidade Tecnológica Federal do Paraná - UTFPR, Campo Mourão-PR. mcaxambu@utfpr.edu.br
} 
Palavras-chave: Arborização urbana; Paisagem urbana; Planejamento urbano; Planejamento ambiental.

\section{ANALYSIS OF THE COMPATIBILITY OF SIDEWALK AFFORESTATION WITH BUILT ENVIRONMENT IN THE LUIZIANA CITY, PARANÁ, BRASIL}

\section{ABSTRACT}

The urban forestry is very important for the environment built by providing improvements in physical, ecological and social environment. For these improvements, it is necessary balance between artificial and natural elements of the environment. The objective of this research was to analyze the compatibility of sidewalk afforestation with the urban infrastructure in the Luiziana, Paraná state. The research used qualitative and quantitative inventory of eight city streets, diagnosing the trees response in the field. There were identified 1540 individual trees, belonging to 47 species, 38 genus and 24 botanical families, the predominant species were Ligustrum Iucidum, Caesalpinia pluviosa, Schinus molle and Murraya paniculata, representing $73,18 \%$ of trees surveyed. The city faces problems related to the management of trees, because $88 \%$ of trees have height of the first bifurcation less than 1,8 meters; also sidewalks and pavement damages by tree roots. Planning is necessary to promote afforestation improvements in physical and visual discomfort caused by the incompatibility of trees with other elements of the urban landscape.

Keywords: Urban afforestation; Urban landscape; Urban planning; Environmental planning.

\section{INTRODUÇÃO}

O ambiente urbano apresenta inúmeros aspectos intervenientes aos sistemas naturais. O crescimento acelerado deste espaço sem planejamento adequado atribui características insalubres à urbe, devido principalmente às ações antrópicas e seus efeitos. A retirada da cobertura vegetal, impermeabilização do solo, poluição sonora, hídrica e visual, dentre outras, são fatores que afetam diretamente a qualidade de vida da população 
citadina e a qualidade ambiental-urbana.

Frente a essa situação, a arborização urbana assume papel fundamental na integração do ambiente natural com as áreas construídas, amenizando potenciais impactos do ambiente construído.

Uma das principais formas de uso das árvores no meio urbano é a arborização viária (BACKES; IRGANG, 2004), onde proporciona o embelezamento da cidade, sombra, nichos para avifauna e entomofauna, minimizam a poluição sonora e visual, apresentam melhorias nas condições microclimáticas, proporcionam bem estar físico e psíquico ao ser humano (GREY; DENEKE, 1978; MILANO, 1988; MILANO; DALCIN, 2000; PIVETTA; SILVA FILHO, 2002; BACKES; IRGANG, 2004; BIONDI; ALTHAUS, 2005; SAMPAIO, 2006).

Entretanto, quando a arborização não é planejada, ou o planejamento é realizado de forma insipiente, os benefícios supracitados são comprometidos, podendo apresentar eventuais transtornos à população e à administração pública, tais como o rompimento de fios de alta-tensão,interrupções no fornecimento de energia elétrica, entupimento em redes de esgotos,obstáculos no calçamento, dentre outros (SILVA FILHO et al., 2002; SILVA FILHO; BORTOLETO, 2005).

Silva (2005) ainda ressalta que a falta de planejamento para a arborização urbana ocasiona grandes despesas para o poder público, com serviços como manutenção, podas frequentes, substituição, remoção e emprego de mão-de-obra excessiva (SILVA, 2005).

Tendo em vista estes fatores faz-se necessário uma avaliação da arborização já existente com o intuito de identificar as falhas do atual planejamento e indicar medidas norteadoras para o manejo da arborização. Segundo Pivetta e Silva Filho (2002), aavaliação/análise da arborização pode realizar-se pela técnica de inventário, a qual permite conhecer as condições da arborização em termos de adaptabilidade e problemas relacionados à espécie e às condições de plantio, para que providências técnicas sejam tomadas.

O principal objetivo desta pesquisa foi a análise da compatibilidade da arborização urbana com as infraestruturas presentes na estrutura viária da cidade de Luiziana, Paraná, com o intuito de subsidiar o manejo pertinente a arborização, promovendo a melhoria nos aspectos visuais da paisagem e a mitigação dos incômodos físicos ocasionados pelas árvores para à administração pública e a população. 


\section{MATERIAL E MÉTODOS}

\section{Caracterização da área de estudo}

O Município de Luiziana localiza-se no Estado do Paraná na Região Centro Ocidental Paranaense. A altitude média da área está em torno de 760 metros acima do nível médio do mar e a uma distância de $428 \mathrm{~km}$ da capital do Estado, Curitiba (IBGE, 2009b). De acordo com o IBGE (2009a), a população estimada em 2007 para o município era de 7.204, sendo a população urbana de 4.350 e a rural, de 2.850 .

Luiziana insere-se no Terceiro Planalto Paranaense (MAACK, 2002). O Município está alocado em um divisor de águas, entre a Bacia Hidrográfica do Ivaí e a Bacia Hidrográfica do Piquirí, recebendo a denominação de Vale do Piquirivaí (CAMPOS, 2005).

De acordo com a classificação climática de Köppen, a área de estudo apresenta clima tipo cfa- Clima subtropical (IAPAR, 2009).

A área fitogeográfica ocupada pelo município compreende uma região onde originalmente ocorre a transição de duas unidades fitoecológicas (ecótono), a Floresta Estacional Semidecidual e a Floresta Ombrófila Mista Montana (IPARDES, 2010). O município apresenta hoje apenas áreas fragmentadas de remanescentes destas duas formações florestais.

\section{Procedimentos técnico-operacionais}

Para a análise da arborização, realizou-se levantamento em 8 (oito) vias da cidade, selecionadas por se localizarem na área central e comportarem a arborização mais antiga. O levantamento deu-se pela técnica de inventário de caráter quali-quantitativo descrito por Milano (1988) e Pivetta e Silva Filho (2002), com o auxílio de uma ficha de campo adaptada de Silva Filho et al. (2002) e Bortoleto (2004). A técnica foi adotada com o intuito de identificar fatores relacionados às características das espécies empregadas na cidade. $A$ ficha de campo levantou as seguintes informações:

(i) Identificação e Localização

- Número de controle: número de identificação atribuído a cada árvore para controle dos dados; 
- Data de coleta: expressa em dia e mês;

- Via: nome do logradouro onde se coletou as informações;

- Número do lote: número do lote em que a árvore estava à frente;

- Calçada: largura da calça em metros;

- Nome da planta: nome vulgar/popular e nome científico.

(ii) Dimensões

- Altura geral da planta;

- Altura da 1a bifurcação: dado coletado somente para indivíduos com altura geral superior a 3 metros;

- Circunferência à Altura do Peito -CAP: dado coletado para indivíduos arbóreos cuja altura da $1^{\text {a }}$ bifurcação fosse superior a 1,30 metros Esta medida foi determinada com o auxílio de uma fita métrica.

(iii) Encontros e interferências:

- Localização geral da árvore: calçada ou canteiro central;

- Localização relativa da árvore: próximo à guia, próximo ao lote ou centrada na calçada;

- Tipo de pavimento:tipo do material de cobertura da calçada onde se encontrava a árvore, dividindo-se em: Terra - quando a calçada apresentava o solo totalmente exposto, Grama- quando a calçada se apresentava somente com gramado, Impermeável - quando a calçada se apresentava pavimentada com concreto e área livre apenas entorno da árvore, Semipermeável - quando a calçada se apresentava pavimentada com material semipermeável e área livre apenas entorno da árvore, Calçada Verde - quando a calçada apresentava parte do passeio com concreto e parte do passeio com gramado);

- Fiação: rede elétrica presente ou ausente sobre o espécime arbóreo;

- Interferência com fiação: existência de interferência na árvore (sim ou não);

- Área Livre: tamanho da área livre em metros. Este dado foi coletado com o auxílio de uma fita trena, dividindo-se nas seguintes classes: Ausente - quando não se evidenciava área livre em torno da árvore; Total - quando a área livre se estendia por toda a calçada, ou seja, não foi evidenciado no passeio qualquer tipo de pavimentação (esta classe comumente foi atribuída para calçadas com o pavimento de terra e/ou grama), e classes expressas em tamanhos métricos, de 0,10 a 0,50 $\mathrm{m}^{2}$, de 0,51 a $1 \mathrm{~m}^{2}$, de 1,01 a $1,5 \mathrm{~m}^{2}$, de 1,51 a $2 \mathrm{~m}^{2}$, de 2,01 a $2,5 \mathrm{~m}^{2}$, e de 2,51 a $3 \mathrm{~m}^{2}$. 
- Situação da raiz: análise visual das condições atuais da raiz, dividindo-se em: Sem Afloramento - quando a raiz encontrava-se totalmente subterrânea, Afloramento na área livre - quando a raiz encontra-se aflorando apenas na área livre, Começando a danificar - quando a raiz apresenta eventuais danos à calçada e construções, Danos moderados - quando o sistema radicular apresenta danos de média intensidade a calçada e construções. Danos severos a calçada - quando a raiz obstruía mais de $50 \%$ da calçada e/ou parte das construções;

- Copa: análise visual da interferência da copa sobre: trânsito de pedestres na calçada e/ou trânsito de veículos na via pública.

(iv) Observações: Espaço destinado à anotação de dados observados em campo que não constam na planilha.

As espécies botânicas foram identificadas por meio das seguintes referências: Árvores brasileiras: manual de identificação e cultivo de plantas arbóreas nativas do Brasil, volumes 1 e 2 (LORENZI, 2002; 2008); Árvores exóticas no Brasil: madeiras ornamentais e aromáticas (LORENZI et al., 2003).

Para os indivíduos em que não foi possível realizara identificação in situ procedeu-se à coleta de material botânico de acordo com técnicas usuais em levantamentos florísticos descrito por Fidalgo e Bonini (1989) e Marchiori (1995). Posteriormente, as amostras foram encaminhadas para identificação ao curador do Herbário do Centro Federal (HCF), professor Doutor Marcelo Galeazzi Caxambu, da Universidade Tecnológica Federal do Paraná, Campus Campo Mourão.

As informações coletadas foram tabuladas em planilhas do Microsoft Excel onde se procedeu a interpretação dos dados através de comandos pré-existentes no programa e a geração de gráficos.

A Circunferência à Altura do Peito foi transformada em Diâmetro à Altura do Peito (DAP) para posterior análise através da Equação1:

Equação 1:

$D A P=\frac{C A P}{\pi}$

Onde:

$\mathrm{DAP}=$ Diâmetro a altura do peito

$\mathrm{CAP}=$ Circunferência a altura do peito

$\Pi=$ Valor de $\mathrm{PI}(3,1415 \ldots)$ 


\section{RESULTADOS E DISCUSSÃO}

\section{Distribuição e composição florística}

Foram analisadas através de inventário um total de 8 vias entre ruas e avenidas na área central da cidade de Luiziana (Tabela 1), perfazendo a extensão de 8.802,43 km de vias trabalhadas. Estas correspondem à arborização mais antiga da cidade e à área com maior predominância arbórea.

Inventariou-se um total de 1.540 indivíduos entre árvores e arvoretas representadas por 47 espécies vegetais, 38 gêneros e 24 famílias botânicas (Tabela 2).

Tabela 1. Vias inventariadas quali-quantitativamente na Cidade de Luiziana, Paraná Table 1. Streets qualitative and quantitative inventariare in Luiziana City, Paraná

\begin{tabular}{lc}
\hline Via & Extensão (m) \\
\hline Av. Independência & $1.970,97$ \\
Av. Liberdade & $1.799,13$ \\
Rua Alaor Deniz Medeiros & $1.707,58$ \\
Rua AntônioRamalheiro & 122,58 \\
Rua Dr. Miguel Vieira Ferreira & 561,77 \\
Rua Presidente Tancredo de Almeida Neves & 697,9 \\
Rua Professora Nilza Macena Bezerra & $1.110,1$ \\
Rua Romão Martins & 832,4 \\
\hline Total & $\mathbf{8 . 8 0 2 , 4 3}$ \\
\hline
\end{tabular}

Tabela 2 - Distribuição quantitativa das espécies arbóreas ocorrentes na arborização viária de Luiziana, Paraná, segundo família botânica, nome científico, nome vulgar/comum, e freqüência (\%); (De acordo com o Sistema de Classificação Botânica APG II)

Table 2 - Quantitative distribution of the occurring tree species in the sidewalk afforestation of Luiziana, Paraná, second botanical family, scientific name, vulgare/common name, and frequency (\%); (According with thebotanical classification system APG II) 


\begin{tabular}{|c|c|c|c|}
\hline Família & Espécie & Nome comum & $\begin{array}{l}\text { Frequência } \\
(\%)\end{array}$ \\
\hline Oleaeceae & Ligustrum Iucidum W.T. Aiton. & Ligustro & 27,01 \\
\hline $\begin{array}{l}\text { Fabaceae- } \\
\text { Caesalpinioideae }\end{array}$ & Caesalpinia pluviosa DC. & Sibipiruna & 19,81 \\
\hline Anacardiaceae & Schinus molle L. & Chorão & 13,96 \\
\hline Rutaceae & Murraya paniculata (L.) Jacq. & Murta & 12,40 \\
\hline Melastomataceae & Tibouchina granulosa (Desr.) Cogn. & Quaresmeira & 6,23 \\
\hline Malvaceae & Hibiscus rosa-sinensis L. & Hibiscuo & 4,48 \\
\hline Lythraceae & Lagerstroemia indica L. & Extremosa & 3,38 \\
\hline Moraceae & Ficus benjamina L. & Ficus & 1,75 \\
\hline Chrysobalanaceae & Licania tomentosa (Benth.) Fritsch & Oiti & 1,17 \\
\hline Bignoniaceae & $\begin{array}{l}\text { Handroanthus heptaphyllus (Vell) } \\
\text { Mattos }\end{array}$ & $\begin{array}{l}\text { Ipê-roxo-de-sete- } \\
\text { folhas }\end{array}$ & 0,78 \\
\hline $\begin{array}{l}\text { Fabaceae- } \\
\text { Caesalpinioideae }\end{array}$ & Delonix regia (Bojer ex Hook.) Raf. & Flamboyant & 0,65 \\
\hline Anacardiaceae & Mangifera indica L. & Mangueira & 0,65 \\
\hline $\begin{array}{l}\text { Fabaceae- } \\
\text { Caesalpinioideae }\end{array}$ & $\begin{array}{l}\text { Caesalpinia ferrea var. leiostachya } \\
\text { Benth }\end{array}$ & Paú-ferro & 0,58 \\
\hline Rosaceae & Eriobotrya japonica (Thunb.) Lindl. & Nêspera & 0,58 \\
\hline $\begin{array}{l}\text { Fabaceae- } \\
\text { Caesalpinioideae }\end{array}$ & Cassia fistula L. & Chuva-de-ouro & 0,52 \\
\hline Solanaceae & Brunfelsia uniflora (Pohl) D. Don & Manacá-de-jardim & 0,45 \\
\hline Lauraceae & Cinnamomum zeylanicum Blume & Canela-da-Índia & 0,45 \\
\hline Rutaceae & Citrus sp. & Limoeiro & 0,45 \\
\hline Myrtaceae & Psidium guajava L. & Goiabeira & 0,45 \\
\hline Myrtaceae & Syzygium cumini (L.) Skeels & Jambolão & 0,39 \\
\hline $\begin{array}{l}\text { Fabaceae- } \\
\text { Cercidade }\end{array}$ & Bauhinia forficata Link & Pata-de-vaca & 0,32 \\
\hline Myrtaceae & Eugenia uniflora L. & Pitangueira & 0,32 \\
\hline Melastomataceae & Tibouchina mutabilis Cogn. & Manacá & 0,32 \\
\hline Meliaceae & Melia azedarach L. & Santa Bárbara & 0,26 \\
\hline Lauraceae & Persea americana Mill. & Abacateiro & 0,26 \\
\hline Rosaceae & Prunus persica (L.) Batsch & Pessegueiro & 0,26 \\
\hline Rutaceae & Citrus sp. & Laranjeira & 0,19 \\
\hline Pinaceae & Pinus elliottii $L$. & Pinus & 0,19 \\
\hline
\end{tabular}




\begin{tabular}{|c|c|c|c|}
\hline Combretaceae & Terminalia catappa L. & Sombreiro & 0,19 \\
\hline Rutaceae & Citrus sp. & Mexerica & 0,13 \\
\hline Myrtaceae & $\begin{array}{l}\text { Eucalyptus grandis W. Hill ex } \\
\text { Maiden }\end{array}$ & Eucalipto & 0,13 \\
\hline Rosaceae & Prunusserrulata Lindl & Cereja-do-Japão & 0,13 \\
\hline Bignoniaceae & $\begin{array}{l}\text { Handroanthuschrysotrichus (Mart. } \\
\text { ex A. DC.) }\end{array}$ & Ipê-amarelo & 0,13 \\
\hline Bignoniaceae & $\begin{array}{l}\text { Handroanthus impetiginosus (Mart. } \\
\text { ex DC.) Mattos }\end{array}$ & Ipê-roxo & 0,13 \\
\hline Myrtaceae & $\begin{array}{l}\text { Campomanesia xanthocarpa O. } \\
\text { Berg }\end{array}$ & Gabiroba & 0,06 \\
\hline Caricaceae & Carica papaya L. & Mamoeiro & 0,06 \\
\hline Moraceae & Ficus sp. & Figueira & 0,06 \\
\hline Rhamnaceae & Hovenia dulcis Thunb. & Uva-do-Japão & 0,06 \\
\hline Aquifoliaceae & Ilex paraguariensis A. St.-Hil. & Erva-mate & 0,06 \\
\hline Bignoniaceae & Jacaranda mimosifolia D. Don & Caroba & 0,06 \\
\hline $\begin{array}{l}\text { Fabaceae- } \\
\text { Mimosoideae }\end{array}$ & Leucaena leucocephala (Lam.) & Leucena & 0,06 \\
\hline Moraceae & Morus nigra L. & Amoreira-preta & 0,06 \\
\hline Annonaceae & Rollinia sylvatica (A. St.-Hil.) Mart. & Araticum-do-mato & 0,06 \\
\hline Solanaceae & Solanum paniculatum L. & Jurubeba & 0,06 \\
\hline Anacardiaceae & Schinus terebinthifolia Raddi & $\begin{array}{l}\text { Aroeira- } \\
\text { pimenteira }\end{array}$ & 0,06 \\
\hline \multirow[t]{2}{*}{ Anacardiaceae } & Spondias purpurea L. & Ciriguela & 0,06 \\
\hline & Não identificada & Boldo & \\
\hline
\end{tabular}

Verifica-se em Luiziana a existência de um número baixo de espécies (47 espécies), quando comparado a estudos conduzidos em outros municípios brasileiros. Bortoleto (2004) cadastrou na Estância Águas de São Pedro-SP um total de 161 espécies, Sucomine (2009) verificou em em São Carlos-SP 103 espécies, Sampaio (2006) constatou em Maringá-PR um total de 84 espécies, Schuch (2006) levantou em São Pedro do Sul-RS 49 espécies, Meneghetti (2003) verificou em Santos-SP, 65 espécies.

Ocorre nas vias trabalhadas à predominância da espécie L. lucidum,querepresenta $27,01 \%$ do total da arborizaçãotrabalhada, seguida por C. pluviosa $19,81 \%$, S. molle $13,96 \%$,e M. paniculata12,40\%. Juntas estas quatro espécies representam $73,18 \%$ do total 
da arborização.

Os valores supramencionados caracterizam uma arborização homogênea, comprometendo a qualidade da mesma e tornando esta população arbórea mais suscetível ao ataque de pragas e doenças. De acordo com Santamour Júnior (1990) a mesma espécie não deve exceder mais que 10\%, o mesmo gênero mais que $20 \%$ e a mesma família botânica mais que $30 \%$ da frequência total da composição florística de determinada área.

No contexto da frequência de indivíduos por gênero, Ligustrum excede valores preconizados por Santamour Júnior (1990), este gênero representa $27,01 \%$ da população arbórea, o gênero Caesalpinia representa 20,39\%. Conclui-se dessa forma, que devem ser evitados novos plantios desses dois gêneros. Ao se tratar de valores referentes a famílias botânicas, verifica-se que nenhuma família botânica excede o valor de 30\% recomendado pelo referido autor.

Independente dos índices preconizados pelo autor, o importante é a heterogeneidade, a diversidade de espécies na arborização, ou seja, ao manejar a arborização de determinada área o gestor deve atentar-se para a variedade de essências florestais distribuídas por ruas e avenidas.

\section{Árvores e rede elétrica}

Ao segregar os dados em classes de alturas, constatou-se que quanto maior o porte arbóreo, maior a interferência entre árvore e rede elétrica. Observa-se que em todos os indivíduos que apresentaram altura de até 3 metros, não foi constatado interferência com fiação, visto que a altura mínima prevista para cabos de telefonia (os quais são os mais baixos) é de 5,40 metros.

$\mathrm{Na}$ classe em que o porte arbóreo oscila de 3,1 a 6 metros, obteve-se valores de $37 \%$ de interferência junto à fiação, todavia, esta classe de altura quando bem manejada apresenta menores riscos de contato visto que as demais árvores desta classe não apresentaram interferência. Na classe de 6,1 a 9 metros observou-se que $96 \%$ dos indivíduos apresentaram interferência entre a copa da árvore e a fiação; nos portes entre 9,1 e 12 metros este percentual cai para 89\% de interferência; nas classes que variam de 12,1 a 15 e 18,1 e 21 metros estaticamente obtiveram-se interferência de 100\%. Para a classe de altura entre 15,1 e 18 metrosnão foi verificada a existência de indivíduos sob a rede elétrica (Figura 1a). Pode-se inferir que a classe de altura mais preocupante em relação a 
interferências é de 6,1 a 9 metros de altura, por situar-se constantemente na faixa da altura da fiação, necessitando frequentemente de técnicas de manejo para adequar-se ao espaço físico disponível. Para as árvores com alturas superiores a 9 metros é possível conduzi-las mecanicamente até passarem a rede elétrica necessitando de podas eventuais ao longo da vida do vegetal.

Nota-se que as espécies de maior incidência junto à fiação correspondem ao $L$. lucidum e C. pluviosa, respectivamente 35\% e 27\%.T. granulosa também apresenta índices relevantes de interferência, 18\%, seguido por S. molle, $9 \%$. A soma das demais espécies apresenta $12 \%$ da montante de interferência (Figura 1b). Também foi evidenciada a interferência relacionada à $C$. ferrea, entretanto, estaticamente, esta não apresenta relevância devido à baixa frequência de indivíduos encontrados na área urbana.

Ao realizar uma análise isolada de cada espécie cuja localização está sob a rede elétrica, o cenário muda. Nota-se que a espécie, cujos indivíduos apresentam maior incidência junto à fiação é C. pluviosa, onde 93,15\% dos indivíduos desta espécie que se localizam sob rede elétrica apresentam algum tipo de interferência, seguidos por $T$. granulosa, com 76,27\%. Já L. lucidum, que no contexto geral apresenta-se como a espécie de maior incidência, quando analisado individualmente, sua proporção de interferência é de $37,13 \%$, onde $62,87 \%$ desses indivíduos não apresentam interferência. S. molle tem uma proporção de 69,74\% de seus indivíduos sem nenhum tipo de interferência (Figura 1c).

Dentre os indivíduos presentes sob a fiação, as seguintes espécies não apresentaram nenhum tipo de interferência, são elas: $P$. americana, S.purpurea, $I$. paraguariensis, L. indica, $P$. guajava, $H$. rosa-sinensis, S. paniculatum, Citrus sp. (Laranjeira), Citrus sp. (Limoeiro), C. papaya, B. uniflora, M. paniculata e E. uniflora.

Ressalta-se que existem outras árvores cadastradas no acompanhamento viário da cidade, que dificilmente venham ocasionar algum tipo de interferência à fiação, entretanto, estas não foram mencionadas visto que não se obteve nenhum representante sob a rede elétrica.

De acordo com McPherson et al. (1999) apud Silva (2005), o efeito da vegetação na cidade diminui gradativamente quando as plantas que estão sendo utilizadas são arbustivas e árvores de pequeno porte. Apesar de estas parecerem apropriadas sob fiação elétrica, apresentam menores benefícios quando comparadas às árvores de maior porte, em providenciar sombra, reter poluição atmosférica e interceptar água da chuva. 
Figura 1. (a) Representação percentual da relação entre altura da árvore e interferência na rede elétrica na Cidade de Luiziana, Paraná. (b) Relação das espécies com maior incidência na rede elétrica das vias na Cidade de Luiziana, Paraná. (c) Análise percentual da interferência das espécies com maior ocorrência de danos à rede elétrica nas vias da Cidade de Luiziana, Paraná

Figure 1. (a) Percentile representation of the relationship between tree height's and interference in the electric net in Luiziana city, Paraná. (b) Relationship of the species with higher incidences in the electric net of streets from Luiziana city, Paraná. (c) Percentile analysis of the interference of the species with higher occurrence of damages to the electric net in streets of the Luiziana city, Paraná

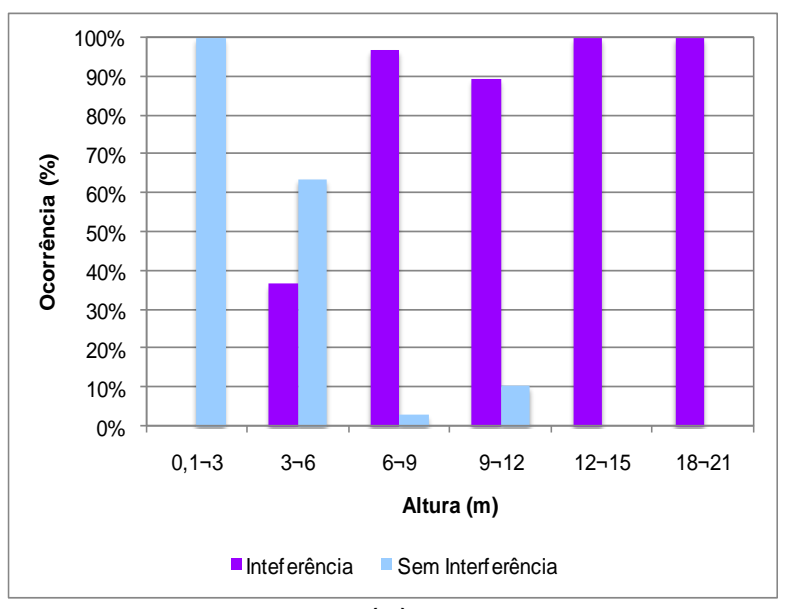

(a)

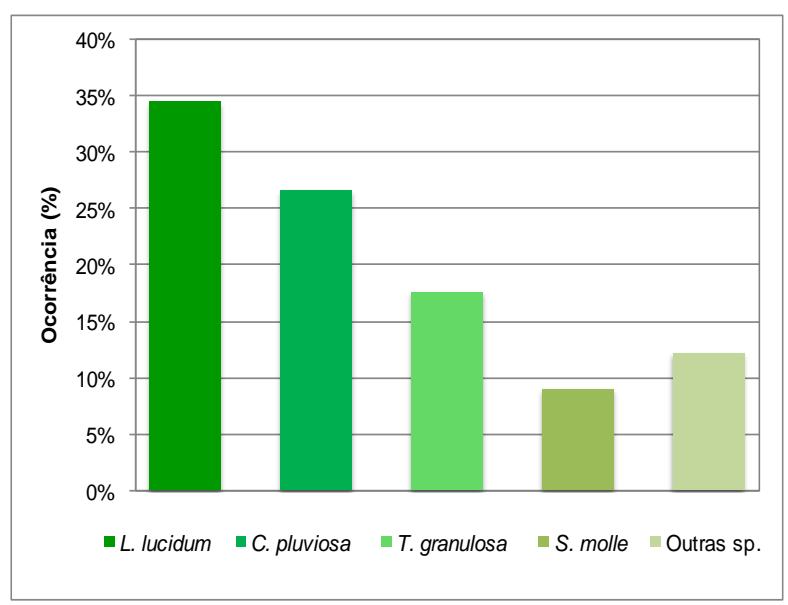

(b)

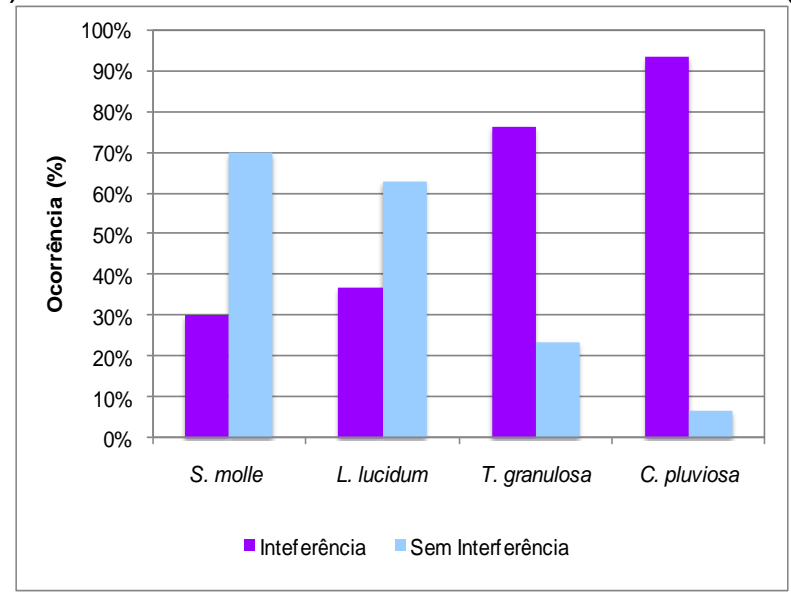

(c)

No momento do plantio é recomendável atentar-se à rede elétrica, visto que árvores de maior porte devem ser plantadas em calçadas sem rede elétrica, ou, no caso de haver 
fiação, há que se observar a condução de maneira adequada, de forma que estas possam ultrapassar a rede elétrica, apresentando danos em pequenas proporções.

\section{Altura da primeira bifurcação}

Segundo Sampaio (2006), a altura da primeira bifurcação pode indicar determinado padrão de qualidade das mudas e da execução de podas de formação. Dentre os indivíduos inventariados, $88 \%$ apresentam altura da primeira bifurcação inferior a 1,8 metros. $O$ valor mínimo de 1,80 metros é desejado para que não ocorra interferência no trânsito de pedestres. Um fator ainda preocupante diz respeito à ocorrência representativa da altura da primeira bifurcação entre 10 a $50 \mathrm{~cm}$,que indica sérios problemas que a cidade tem com 0 manejo inadequado das árvores, principalmente na condução de mudas recémplantadas(Figura 2).

Figura 2. Frequência das classes da altura da primeira bifurcação das árvores presentes no acompanhamento viário da cidade de Luiziana, Paraná

Figure 2. Frequency of height of the first bifurcation classes present in the sidewalk afforestation of the Luiziana city, Paraná

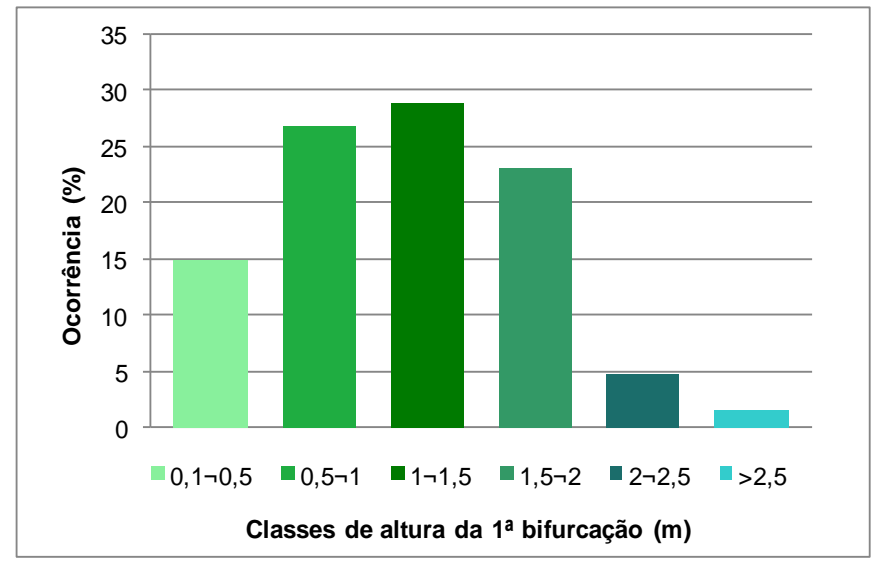

Em estudo realizado por Almeida (2009) em cinco cidades do Mato Grosso - Matupá, Nova Monte Verde, Alta Floresta, Colíder e Carlinda -, obteve-se frequências para a primeira bifurcação abaixo de 1,80 metros similares aos de Luiziana, respectivamente $84,5 \%, 88,1 \%$, $88,4 \%, 96,7 \%$ e $97,8 \%$, indicando que esse problema de condução de mudas recémplantadas ocorre em outras localidades. 
Dentre as espécies com maior frequência de altura da primeira bifurcação inferior a 1,8 metros estão, L. lucidum (34,07\%), C. pluviosa (29,74\%), S. molle $(13,58 \%)$ e $T$. granulosa $(9,13 \%)$, as demais espécies representam menos que $2,5 \%$ cada. Visto que $T$. granulosa no contexto geral da arborização não apresenta muitos indivíduos, estes $9 \%$ de frequência apresenta grande grau de importância.

Ao segregar as espécies com a altura da primeira bifurcação superior a 1,80 metros tem-se a seguinte situação: C. pluviosa representa 40,54\% das árvores com a primeira bifurcação superior a 1,80 metros, seguidapor L. lucidum com 27,03\%, S. molle com 10,14\%, e T. granulosa com 7,43\%.

As quatro espécies com maiores frequências da primeira bifurcação superior a 1,80 metros são também as 4 espécies com maiores frequências da primeira bifurcação inferior a 1,80 metros. Esta incongruência entre os dados ocorre pelo fato destas espécies corresponderem às espécies de maior ocorrência na arborização trabalhada.

\section{Diâmetro à altura do peito}

De acordo com Forman e Godron (1986) apud Sucomine (2009) o Diâmetro a Altura do Peito (DAP) podem dar indicações da maturidade de determinadas espéciesarbóreas (quanto maior o DAP, maior a maturidade do espécime).

Verifica-se em Luiziana que asclasses de DAP entre 30 a $40 \mathrm{~cm}$ e 20 a $30 \mathrm{~cm}$ representam $29,21 \%$ e $26,49 \%$, respectivamente, do total de árvores, tendo em vista a firmação supramencionada (FORMAN; GODRON, 1986 apud SUCOMINE, 2009) pode-se inferir que a comunidade arbórea da cidade é representada por árvores jovens em transição para adultas. Os valores de $21,78 \%$ da classe que varia entre 10 e $20 \mathrm{~cm}$ também indicam novos plantios (Figura 3) corroborando a ideia de Silva (2005), na qual é desejável manter um alto número de indivíduos jovens plantados, com o intuito de garantir uma constante na comunidade de árvores, pois quando as árvores adultas estiverem mortas, as jovens estarão adultas e assim sucessivamente. 
Figura 3. Frequência das classes de Diâmetro à Altura do Peito (DAP) das espécies arbóreas presentes no acompanhamento viário da cidade de Luiziana, Paraná

Figure 3. Frequency of classes of diameter at breast height (DBH) of tree species present in sidewalk afforestationLuiziana city, Paraná

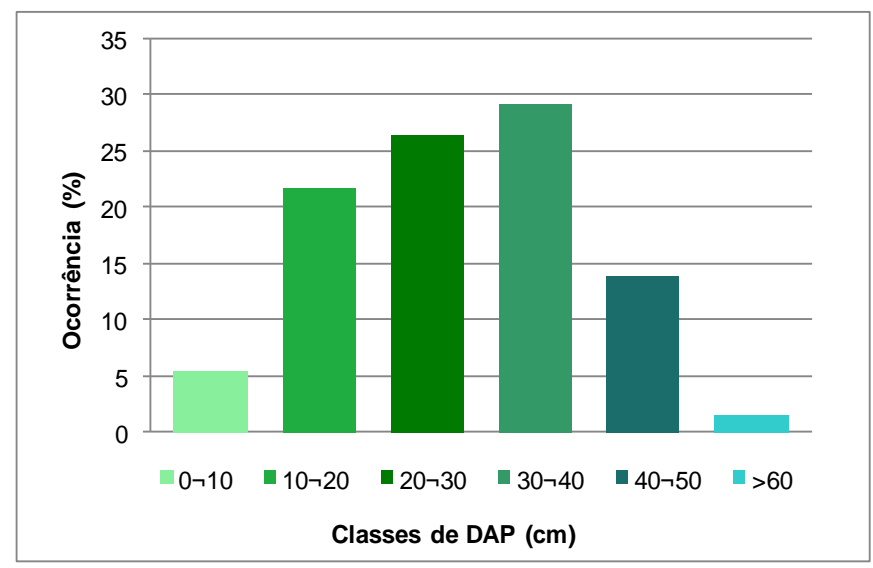

\section{Localização e interferências}

A árvore urbana encontra-se ilhada num mar de construções civis. A calçada, a pavimentação viária, as edificações e os equipamentos urbanos interferem na dinâmica do seu desenvolvimento natural (VOLPE-FILIK, 2009).

Para que a árvore tenha uma boa adaptabilidade neste ecossistema construído, necessita-se da adoção de critérios específicos para a locação da planta, com a finalidade de evitar futuros conflitos entre árvore e infraestruturas.

Verifica-se que dentre os 1.540 indivíduos qualificados, 89\% estão dispostos nas calçadas e $11 \%$ no canteiro central, sendo que a cidade apresenta apenas uma via composta por canteiro central, a Avenida Independência, via estruturadora que atravessa a área urbana.

No que diz respeito à localização relativa da árvore, ou seja, a localização espacial do indivíduo nas calçadas nota-se uma ausência de padronização, ora a árvore esta próxima ao lote, ora próxima a via e ora centralizada. Verifica-se $54 \%$ dos indivíduos centradas, $41 \%$ junto à guia e $5 \%$ junto ao lote. A distribuição destas no passeio público pode eventualmente afetar no trânsito de pedestres, relacionando-se diretamente com a largura da calçada e com a área ocupada pelas mesmas.

Existe relação entre a localização da planta na calçada e a interferência destas, 
ocasionada pela copa no trânsito de veículos e pedestres. Nota-se que $78 \%$ das espécies em cada classe (centrada, junto à guia e junto ao lote) não apresentam interferência alguma no trânsito. Observa-se também que os incômodos ocasionados pelas copas das árvores, são mínimos para os pedestres, mas ainda sim, é verificável a existência de interferência (Figura 4a).

As interferências ocasionadas pela copa das árvores representam 17\% para árvores centradas, 19\% para árvores junto à guia, e 16\% para árvores junto ao lote. Interferências no trânsito de veículos e interferência concomitante no trânsito de veículos e pedestres representam menos de $5 \%$ em cada uma das classes (centrada, junto à guia, junto ao lote) (Figura 4a).

Tendo em vista que a interferência mais representativa diz respeito ao trânsito de pedestres, as espécies mais frequentes são: L. lucidum, C. pluviosa, S. molle, M. paniculata, T. granulosa e $H$. rosa-sinensis, respectivamente $27 \%, 19 \%, 12 \%, 6 \%$, e $4,5 \%$, as demais espécies correspondem a 16\% (Figura 4b). Nota-se que as espécies de maior interferência no trânsito são as de pequeno e médio porte.

Figura 4. (a) Relação entre a localização relativa das espécies e a interferência ocasionada pela copa no trânsito de pedestres e veículos na Cidade de Luiziana, Paraná. (b) Relação das espécies de maior interferência no trânsito de pedestres na Cidade de Luiziana, Paraná

Figure 4. (a) Relationship between relative location of the species and interference caused by the crown in pedestrian traffic and vehicles in the Luiziana city, Paraná. (b) Relationship of species with higher interference in pedestrian traffic in the Luiziana city, Paraná

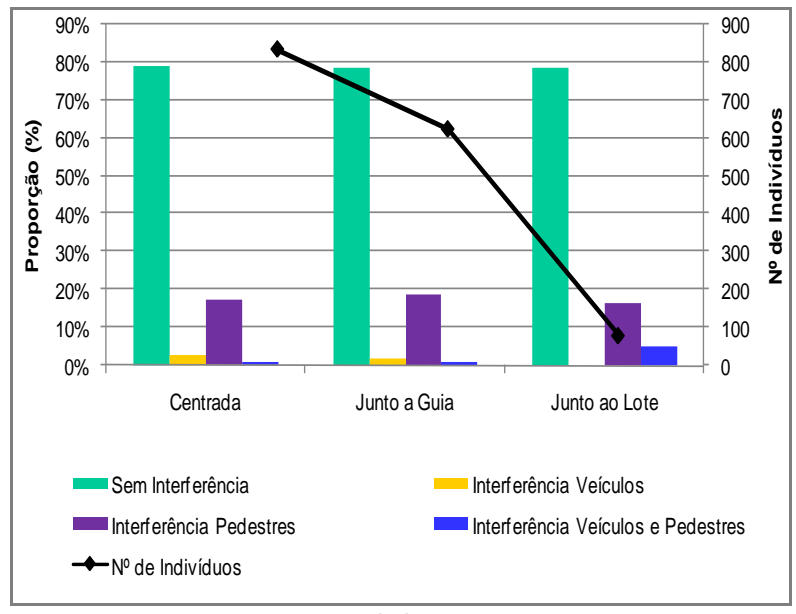

(a)

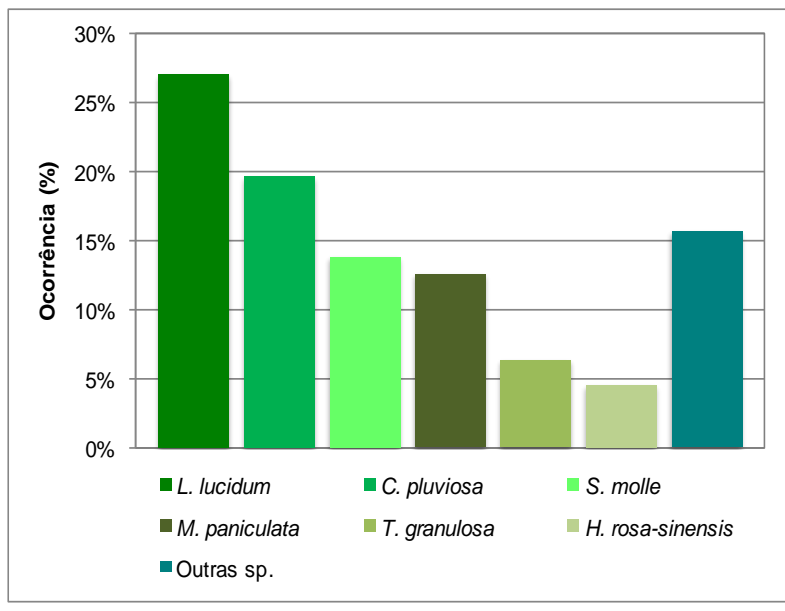

(b) 


\section{Sistema radicular e calçamento}

\section{a) Passeio público em Luiziana}

Os passeios públicos (calçadas) devem apresentar características especificas para que ocorra certa equidade entre árvore e pedestre, com o intuito de evitar futuros transtornos à população bem como a administração pública, ao quebrar calçadas e ser incompatível com outras infraestruturas urbanas.

Segundo São Paulo (2005), a largura mínima de calçada desejável para o plantio de árvores é de 2,4 metros. Em calçadas com largura inferior a 1,5 metros não se recomenda o plantio de árvores; para larguras entre 1,5 a 2 metros, o plantio de espécies arbustivas e pequeno porte, desde que bem conduzidas para que sua copa interfira no espaço destinado ao pedestre; em passeios com largura igual ou superior a 2 metros e inferior a 2,4 metros, o plantio de árvores de pequeno e médio porte; em passeios com largura igual ou superior a 2,4 e inferior a 3 metros, o plantio de árvores de pequeno, médio e grande porte com alturas de até 12 metros;já nos passeios com largura igual ou superior a 3 metros, recomenda-se o plantio de árvores de pequeno, médio e grande porte.

Os parâmetros supracitados também devem ser combinados no momento do plantio com a escolha adequada da essência florestal a ser empregada e com a presença ou não de fiação no local.

Em Luiziana foramconstatadas larguras de calçadas que vão de 1,6 a5 metros, $56,36 \%$ das árvores estão presentes em calçadas entre 2,6 a3,6 metros, seguidos por $29,16 \%$ dos indivíduos presentes em calçadas entre 3,6 a4,6 metros. Com exceção do canteiro central na Avenida Independência, o qual possui uma largura de 1,6 metros sem área pavimentada, as demais calçadas presentes na classe 1,6 a 2,6 estão acima de 2 metros (Figura 5). 
Figura 5. Frequência das classes das larguras das calçadas na cidade de Luiziana, Paraná Figure 5. Frequency of widths sidewalks classes in the Luiziana city, Paraná

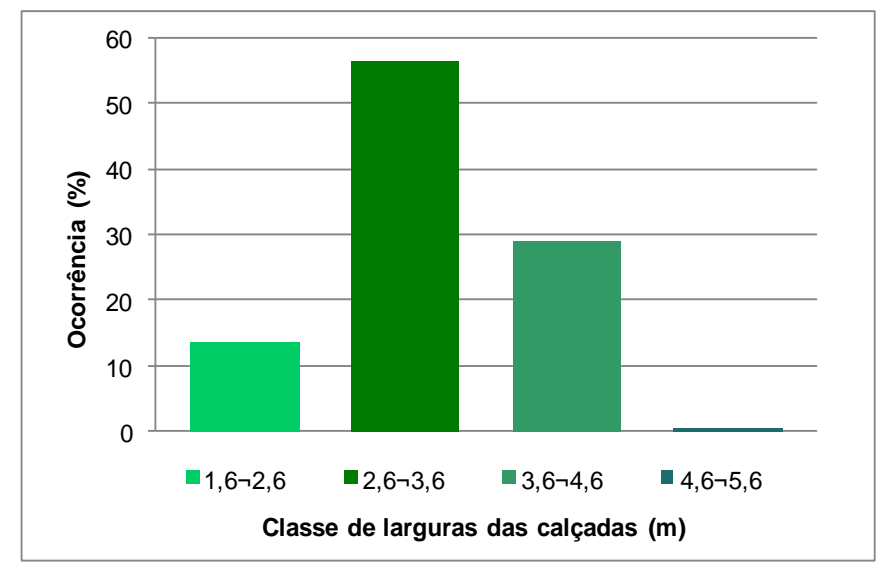

Constata-se que as vias trabalhadas dispõem de um bom espaço físico para o plantio de árvores, faz-se necessário a escolha de espécimes compatíveis ao espaço físico disponível bem como a condução e manejo adequado, uma vez que é mais viável economicamente comportar a árvore ao desenho urbano existente, do que comportar o desenho a árvore. Novos loteamentos podem prever espaços mais adequados para as árvores em seu planejamento.

\section{b) Tipo de pavimento}

Verifica-se que $8,25 \%$ das árvores estão presentes na categoria intitulada de "calçada verde", 14,55\% em calçadas com "gramado", 37,53\% em calçadas somente com terra e 39,68\% em passeios com material impermeável (Figura 6).

O modelo de calçada em que a árvore foi plantada exerce grande influência na qualidade da planta, principalmente no que diz respeito à drenagem e à compactação do solo, uma vez que ambos os fatores interferem na quantidade e qualidade dos nutrientes que estão disponíveis à planta.

Os tipos de calçadas mais frequentes em Luiziana (terra e material impermeável) podem não contribuir para um bom desenvolvimento das árvores. A categoria intitulada de "terra" caracteriza-se pela presença de solo exposto, podendo ocasionar a compactação 
(principalmente em solos com características argilosas), processos erosivos, aumentar o escoamento superficial e reduzir a infiltração da água da chuva, afetando diretamente na disponibilidade hídrica, nutricional e estética da planta; já na calçada intitulada como "impermeável" caso não se tenha a área livre superior a $1 \mathrm{~m}^{2}$ (recomendada por MILANO e DALCIN, 2000 para a arborização de vias), não propicia um ambiente adequado para o desenvolvimento do vegetal, visto a impossibilidade ou baixa infiltração de água.

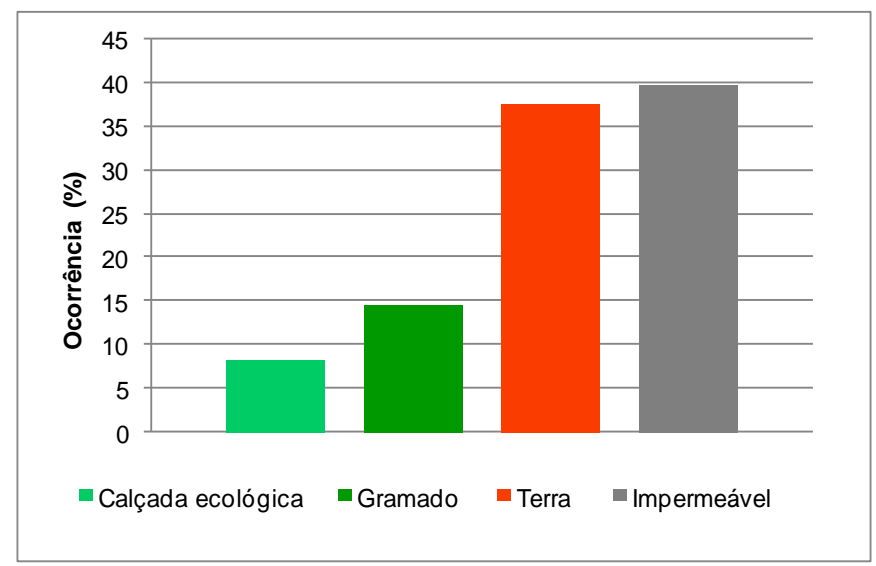

Figura 6. Distribuição percentual dos indivíduos arbóreos em cada tipo de calçada

Figure 6. Percentile distribution of tree individual in each type of sidewalks

É desejável é que a planta esteja em uma calçada do tipo verde, uma vez que esse modelo de calçada propicia um passeio adequado para o transeunte, bem como espaço satisfatório para o desenvolvimento do indivíduo arbóreo.

\section{c) Área Livre e danos ao calçamento}

Verifica-se em Luiziana que 53,05\% das árvores estão presentes em calçadas com a área livre classificada como "Total", 32,53\% em áreas livres classificadas de 0,5 a $1 \mathrm{~m}^{2}$, $8,25 \%$ em área livre de 1 a $1,5 m^{2}$, para as classes de área livre superiores a $2 m^{2}$ evidenciase valores inferiores a $1 \%$ do montante, ainda nota-se um total de 1,36\% para árvores presentes na classe intitulada como "área livre ausente" (Figura 7a).

Ao que diz respeito entre o tipo de área livre e o tipo de dano, a maior incidência de danos está na classe de área livre intitulada de "Ausente", os danos severos nesta classe correspondem a aproximadamente $38 \%$, esta foi à classe em que os danos severos 
atingiram maiores percentuais, ainda para a classe intitulada de "Ausente" verifica-se aproximadamente $15 \%$ de danos moderados e $23 \%$ das árvores apresentam raízes começando a danificar o calçamento e construções. Em contrapartida a classe em que não se evidenciou tipo algum de dano foi a com área livre entre 2,5 a $3 \mathrm{~m}^{2}$, o "afloramento na área livre" corresponde a $100 \%$ das árvores trabalhadas, esta classe de largura de área livre é a mais compatível com o calçamento (Figura $7 b$ ).

Figura 7. (a) Relação existente entre tipo de área livre e o sistema radicular da planta; (b) Tamanho das áreas livres presentes no passeio público de Luiziana, Paraná

Figure 7. (a) Relationship between type of free area and the plant's root system, (b) Size of free areas present on sidewalks of Luiziana, Paraná

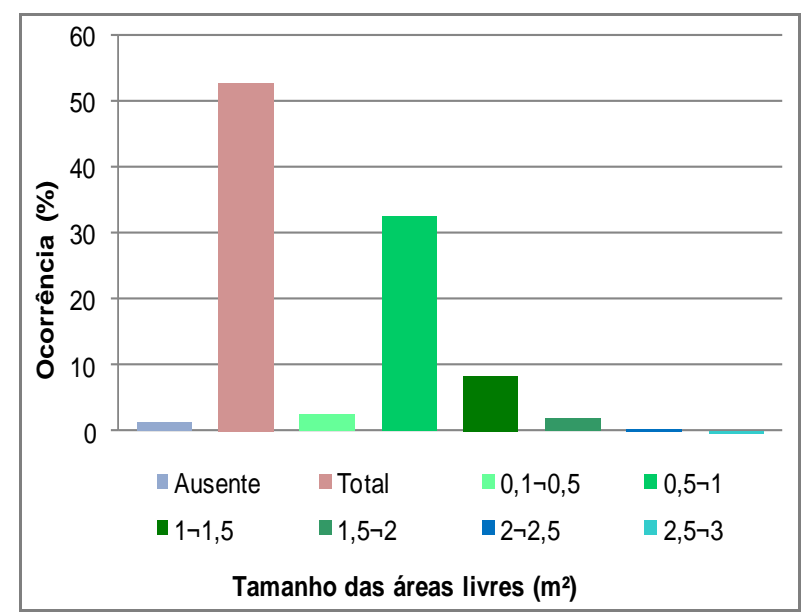

(a)

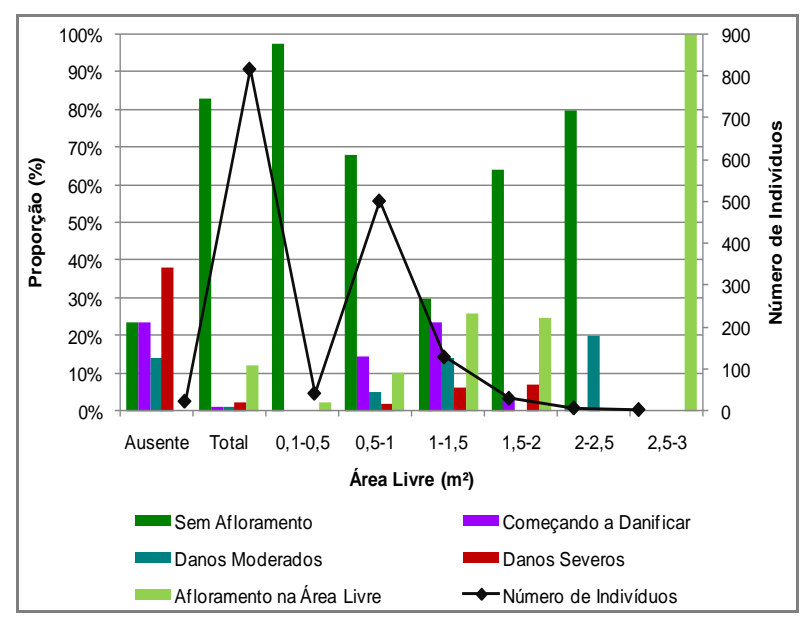

(b)

As espécies que apresentaram maior frequência de danos ao calçamento foram: $D$. regia, L. lucidum (Figura 8b), C. pluviosa, C. fistula, C. ferrea, e T. granulosa. Os problemas associados ao sistema radicular, geralmente são advindos da má condução do plantio do espécime bem como as podas efetuadas ao longo do crescimento da planta. 
Figura 8. Vista parcial de danos ocasionados pelas raízes do Ligustrum lucidum W.T. Aiton na Avenida Liberdade em Luiziana, Paraná.

Figure 8. Half view of damage caused by roots of Ligustrum lucidum W.T Aiton in Liberdade Avenue of Luiziana, Paraná.

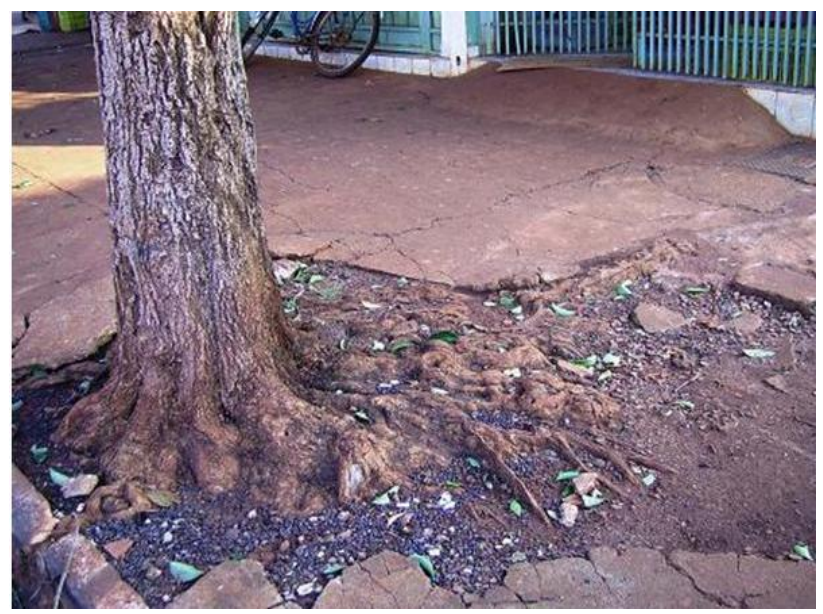

\section{CONCLUSÕES}

Verificou-se nas vias trabalhadas uma distribuição arbórea regular, porém um baixo número de espécies, apresentando-se a população arbórea homogênea, sendo necessário o incremento de novas essências florestais.

Com base nos dados apurados conclui-se que, a arborização existente nas vias trabalhadas é incompatível com os elementos construídos (infraestrutura) da paisagem urbana. Não se pode atribuir esta incompatibilidade às espécies trabalhadas, mas sim, a ausência ou até mesmo a insipiência de manejo adequado da arborização, como exemplo o fato de $88 \%$ das espécies apresentarem altura da primeira bifurcação inferior a 1,8 metros.

Sendo assim, não se sabe qual seria o real comportamento/compatibilidade destas espécies com as infraestruturas caso tivesse um manejo adequado, todavia, infere-se que práticas adequadas de manutenção das árvores apresentariam melhores resultados de compatibilidade, tornando a relação infraestrutura/planta menos conflitante.

Entretanto, frente à situação existente, a espécie que apresentou maior incompatibilidade com os elementos trabalhados, foi $L$. lucidum, em contrapartida as espécies que apresentaram pouca ou nenhuma interferência foram: $L$. tomentosa, $B$. 
forficata, E. uniflora, T. mutabilis, $H$. chrysotrichus, $P$. serrulata, $H$. impetiginosus.

Um fator que merece destaque diz respeito à área livre disponível para a planta em calçadas pavimentadas com material impermeável, perante os resultados obtidos considerase adequada para a situação trabalhada a área livre (gola da árvore) superior a $2 \mathrm{~m}^{2}$, uma vez que valores inferiores a esta medida são mais suscetíveis a danos ocasionados pelo sistema radicular da planta.

Apesar do manejo da arborização não ter sido aqui abordado de maneira enfática, acredita-se que este é o fator condicionante a compatibilidade da espécie empregada para com as infraestruturas, ou seja, dependendo da essência florestal cultivada, esta necessitará de maior ou menor manejo para apresentar adequabilidade ao ambiente construído.

Ressalta-se a necessidade de novos trabalhos que visem o (re) planejamento da arborização, bem como pesquisas que tenham como foco a baixa diversidade de espécies, e a empregabilidade de espécies exóticas presentes na área, com o intuito de nortear um manejo mais preciso da arborização viária, para que a árvore seja um elemento integrador à paisagem urbana.

\section{REFERÊNCIAS}

ALMEIDA, D. N. Análise da arborização urbana de cinco cidades da região Norte do estado do Mato Grosso. 2009. 71p. Dissertação (Mestrado em Ciências Florestais) Faculdade de Engenharia Florestal. Universidade Federal do Mato Grosso. Cuiabá, 2009.

ANDRADE, T. O. Inventário e análise da arborização viária da estância turística de Campos do Jordão, SP. 2002. 128p. Dissertação (Mestrado em Agronomia) Escola Superior de Agricultura. Piracicaba, Universidade de São Paulo, 2002.

BACKES, P.; IRGANG, B. Árvores cultivadas no sul do Brasil: guia de identificação e interesse paisagístico das principais espécies exóticas. Porto Alegre: Paisagem do Sul, 2004.

BIONDI, D.; ALTHAUS, M. Árvores de Rua de Curitiba: cultivo e manejo. Curitiba: FUPEF, 2005. 
BORTOLETO, S. Inventário quali-quantitativo da arborização viária da Estância de Águas de São Pedro. Piracicaba, 2004. 99p. Dissertação (Mestrado em Agronomia) Escola Superior de Agricultura "Luiz de Queiroz". Universidade de São Paulo, 2004.

CAMPOS, J. B. (coord.). Plano de Manejo do Parque Estadual Lago Azul. Curitiba: IAP/DIBAP, 2005.

FIDALGO, O.; BONONI, V. L. R. Técnicas de Coleta: preservação e herborização de material botânico. São Paulo: Instituto de Botânica, 1989.

GREY, G. W.; DENEKE, F. J. Urban Forestry.New York: John Wiley, 1978.

IAPAR (Instituto Agronômico do Paraná). Cartas Climáticas do Paraná. Disponível em: <http://www.iapar.br/modules/conteudo/conteudo.php?conteudo=863> Acesso em: 13 ago. 2009.

IBGE. População. Disponível em: http://www.sidra.ibge.gov.br. Acesso em: 20 mar. 2009a.

Histórico de Luiziana. Disponível em: <http://biblioteca.ibge.gov.br>. Acesso em: 17 mar. 2009b.

IPARDES. Cobertura vegetal original do estado do Paraná. Disponível em:< http://www.ipardes.gov.br/modules/conteudo/conteudo.php?conteudo=134 > Acesso em: 10 fev. 2010.

LORENZI, H. Árvores brasileiras: manual de identificação e cultivo de plantas arbóreas nativas do Brasil. Vol. 1, 5 ed. Nova Odessa: Plantarum, 2008.

Árvores brasileiras: manual de identificação e cultivo de plantas arbóreas nativas do Brasil. Vol. 2. 2 ed. Nova Odessa: Plantarum, 2002.

LORENZI, H.; SOUZA, H. M.; TORRES, A. V. Árvores Exóticas no Brasil: Madeireiras, Ornamentais e Aromáticas. Nova Odessa: Instituto Plantarum, 2003. 
MAACK, R. Geografia física do Estado do Paraná. Curitiba: Imprensa Oficial, 2002.

MARCHIORI, J. N. C. Elementos de Dendrologia. Santa Maria: UFSM, 1995.

MENEGHETTI, G. I. P. Estudo de dois métodos de amostragem para inventário da arborização de ruas dos bairros da orla marítima do município de Santos- SP. 2003. 100p. Dissertação (mestrado em Ciências Agrárias). Escola Superior deAgricultura "Luiz de Queiroz". Universidade de São Paulo, Piracicaba, 2003.

MILANO, M. S. Avaliação quali-quantitativa e manejo da arborização urbana: exemplo de Maringá-PR. 1988. 120p. Tese (Doutorado em Engenharia Florestal). Universidade Federal do Paraná, Curitiba, 1988.

MILANO, M.; DALCIN, E. Arborização de vias públicas. Rio de Janeiro: Light, 2000.

PIVETTA, K. F. L.; SILVA FILHO, D. F. Arborização Urbana. Boletim Acadêmico. Jaboticabal: UNESP/FCAV/FUNEP, 2002.

SAMPAIO, A. C. F. Análise da arborização de vias públicas da área piloto de Maringá. 2006. 116p. Dissertação (Mestrado em Geografia). Universidade Estadual de Maringá, Maringá, 2006.

SANTAMOUR JÚNIOR, F.S. Trees for urban planting: diversity uniformity, and common sense. In: Metria Conference, 7. 1990, Proceedings. Lisle: p.57-66, 1990.

SÃO PAULO. Manual técnico de arborização urbana. São Paulo: Secretária do verde e meio ambiente, 2005.

SCHUCH, M. I. S. Arborização urbana: uma contribuição à qualidade de vida com o uso de geotecnologias. 2006. 101p. Dissertação (Mestrado em Geomática). Universidade Federal de Santa Maria. Santa Maria, 2006.

SILVA FILHO, D. F.; PIVETTA, P. V. C.; AlMeidA, J. B. S. A.; PIVetTA, K. F. L.; FERRAUDO, A. S. Banco de dados relacional para cadastro, avaliação e manejo da 
arborização urbana. Rev. Árvore. Viçosa, v.26, n.5, p.629-642, 2002.

SILVA, L. F. Situação da arborização viária e proposta de espécies para os bairros Antônio Zanaga I e II, da cidade de Americana-SP. 2005. 80p. Dissertação (Mestrado em Agronomia) Universidade de São Paulo, Piracicaba, 2005.

SUCOMINE. N. M. Caracterização e análise do patrimônio arbóreo da malha viária urbana central do município de São Carlos-SP. 2009. 110p. Dissertação (Mestrado em Engenharia Urbana). Universidade Federal de São Carlos. São Carlos, 2009.

VOLPE-FILIK, A. Trinca nas calçadas e espécies muito utilizadas na arborização: comparação entre Sibipiruna (Caesalpinia pluviosa DC.) e Falsa-murta (Murraya paniculata (L.) Jacq.), no município de Piracicaba/SP. 2009. 96p. Tese (Doutorado em Agronomia) - Escola Superior de Agricultura Luiz de Queiroz. Universidade de São Paulo. Piracicaba, 2009. 